\title{
THERAPEUTIC ACTION OF A PITUITARY EXTRACT IN RETINITIS PIGMENTOSA*
}

\author{
BY \\ O. Conti, J. C. Mussio-Fournier, P. Carriquiry, \\ and F. GONZALEZ VANRELL \\ Instituto de Endocrinologia, Hospital Pasteur, Montevideo, Uruguay
}

ONE of the theories put forward to explain retinitis pigmentosa attributes this condition to endocrine disorders. Several authors, among them Bardet (1919) and Bing (1931), have suggested that the adiposo-genital dystrophy seen in the Laurence-Moon-Biedl syndrome is of hypophyseal origin; the first to state that the disease as a whole was due to a diencephalic lesion was Sterling (1930). Zondek and Koehler (1932) maintained that ordinary retinitis pigmentosa, as well as that observed in the LaurenceMoon-Biedl syndrome, was due to hypophyso-tuberal changes. These theories have led to the trial of total pituitary extracts in the treatment of retinitis pigmentosa. W $V$ ith this medication, Reilly and Lisser (1932) obtained a favourable effect upon the visual acuity of a patient with the Laurence-Moon-Biedl syndrome. Viallefont (1936) found improvement in visual acuity and hemeralopia in three cases of retinitis pigmentosa. Pesme and Hirtz (1937), treating a case of Laurence-Moon-Biedl syndrome in this manner, obtained an improvement in vision with a decrease in photophobia and nystagmus. Jores (193:3), instilling melanotropic hormone into only one eye, in man, found an increased rate of dark adaptation in that eye. This led Basile (1939) to use a pituitary extract containing this hormone in the treatment of retinitis pigmentosa; he used it in subconjunctival and subcutaneous injections and in instillations, and obtained an improvement in the hemeralopia in several cases of retinitis pigmentosa, but not in visual acuity. Gonzalez Vanrell and others (1948; 1949) also obtained an evident improvement in visual acuity in this disease by the use of subcutaneous injections of an extract containing melanotropic hormone. Later, MussioFournier and others (1949) obtained favourable results in retinitis pigmentosa with conjunctival instillations of an extract having a high content of melanotropic hormone.

* Received for publication May 11, 1950, 


\section{Treatment}

The extract used is prepared from intermediate and posterior lobes of bovine hypophyses; it has no oxytocic or vasopressor effect, but has an intense melanotropic action. It is used both in the form of subcutaneous injections and in ocular instillations. The injectable extract contains 400 frog units per $\mathrm{ml}$. and is generally given in twice weekly injections of $1 \mathrm{ml}$. The extract prepared for instillation contains $16,000 \mathrm{~L}$. per $\mathrm{ml}$.; it has a similar $p H$ to that of the lacrimal secretion, and is more or less isotonic therewith. We have generally made two instillations per week, but the frequency depends upon the results obtained. Thus, in some cases, the favourable effect of each instillation only lasts two or three days, while in others we have seen it extend to 15 or 20 days or even two months. Three drops are instilled into each eye at $5^{\prime}$ intervals between drops, and $30{ }^{\prime}$ to (60) after the last drop the effect upon the vision is checked. In the majority of cases with favourable results, these appear within this time.

The histories of 22 cases treated with pituitary extract are given below.

\section{Case Histories*}

Case 1.-S.S., male, aged 23 years, seen in March, 1947. Typical retinitis pigmentosa with posterior capsulo-lenticular opacities. Visual acuity: R.E., 0.2; L.E., 0.4. Visual field showing a concentric constriction close to the fixation point. Treatment was begun with injections of extract and three months later vision was 0.7 in the right eye and 0.4 in the left. Hemeralopia and photophobia had decreased and headache, which had long been present, disappeared. By February, 1948, vision reached R.E. 0.9 and L.E. 0.7. Treatment has been continued regularly since then except for an absence of patient from city lasting 45 days, at the end of which vision had fallen to R.E. 0.7 and L.E. 0.5. One hour after instillation former values were recovered. On March 17, 1949, vision was: R.E., unity; L.E., 0.8. There were no fundus or field changes.

Case 2.-M.G., male, aged 28 years. Seen March, 1947. Typical retinitis pigmentosa. Vision: 0.5 in both eyes. Astigmatism, correction of which does not increase vision. Visual field: ring scotoma from $10^{\circ}$ to $30^{\circ}$. Treatment with injections was begun, and on July 4,1947 , visual acuity was R.E. 0.9 and L.E. 0.7 . Hemeralopia and photophobia had decreased. On October 30, 1947, vision was 0.9 in each eye. Patient has been lost sight of since then.

Case 3.-B.R., male, aged 54 years. Seen February, 1947. R.E. with typical retinitis pigmentosa. L.E. long since enucleated. Vision without correction: R.E. counts fingers at $30 \mathrm{cms}$. Lenticular opacities. In March, 1947, treatment was begun with subcutaneous injections, twice weekly, of the pituitary extract. On July 4, 1947, vision was 0.2. Patient was now able to go about the streets alone. Treatment was continued and in April, 1950, vision was 0.6. Hemeralopia and photophobia improved. No improvement in visual field.

Case 4.- J.B., male, aged 48 years. Seen June, 1947. Retinitis pigmentosa. Vision: R.E. 0.04; L.E. 0.02. Treated with injections. On November 17, 1947, vision was: R.E. $0 \cdot 1$ and L.E. 0.04. Patient during this time did not follow treatment regularly and was lost sight of after the date mentioned.

\footnotetext{
* Visual acuity is given according to the International Decimal Scale.
} 
Case 5.-A.S.B., female, aged 37 years. Seen June, 1948. Retinitis pigmentosa. Vision: R.E. 0.5; L.E. 0.3. Visual fields constricted to within $10^{\circ}-15^{\circ}$ of fixation point. Two injections were given per week, and after the twentieth injection vision reached unity. The hemeralopia improved. Visual fields remained the same.

Case 6.-V.A., male, aged 49 years. Seen April, 1948. Retinitis pigmentosa. Vision: 0.6 in both eyes. Slight lenticular opacities of congenital appearance. Signs of sclerosis in the arteries of the fundi, consistent with hypertension. Visual fields constricted to $10^{\circ}$ of fixation point. After 20 injections vision became normal. Hemeralopia improved. From October, 1948, until July 31, 1949, treatment was continued with one injection per week, the improvement persisting.

Case 7.-F.P.F., male, aged 56 years. Seen November 17, 1948. Retinitis pigmentosa. Advanced sclerosis of both lenses. Chronic simple glaucoma. Vision: R.E. 0.25 ; L.E. 0.25 . Visual fields constricted to $5^{\circ}-7^{\circ}$ of fixation point. With injections and four instillations vision reached 0.5 in both eyes on January $5,1949$. In the right eye visual field increased $5^{\circ}$ on some meridians.

Case 8.-P.D., male, aged 54 years. Seen on November 12, 1948 . Retinitis pigmentosa. Vision with correction: 0.5 in both eyes. Fields reduced to within $5^{\circ}$ of fixation point. On this date, after an instillation, vision reached 0.7 in both eyes. Instillations were continued and on December 21, 1948, corrected vision reached 0.9 in both eyes. In February, 1949, fields had increased $3^{\circ}$ on some meridians. Hemeralopia improved. An improvement is obtained in the photophobia, but only lasting 24 hours after each instillation. Treatment was continued and on July 20,1949, improvement persisted.

Case 9.-M.F.C., female, aged 61 years. Seen November, 1948. Retinitis pigmentosa. Vision: R.E. 0.3; L.E. 0.15 . Fields constricted to within $2^{\circ}-4^{\circ}$ of fixation point. On April 20, 1949, after a series of 40 injections and 4 instillations, vision was 0.5 (doubtful) in both eyes. Hemeralopia had improved. Fields unchanged.

Case 10.-H.F.I., female, aged 58 years. Seen November 17, 1948. Retinitis pigmentosa. Chronic simple glaucoma and advanced opacity of both lenses. Vision: R.E. 0.3; L.E. $0 \cdot 15$. Superior fields narrowed to within $6^{\circ}$ or $8^{\circ}$ of fixation point; inferior fields to within $18^{\circ}$ or $22^{\circ}$. On April 20, 1949, after 40 injections and 4 instillations, vision was 0.5 in both eyes. Fields had increased as much as $4^{\circ}$ on some meridians. Hemeralopia had not improved.

Case 11.-M.D.T., female, aged 38 years. Seen January 18, 1949. Vision: 0.5 in both eyes. Fields constricted to within $2^{\circ}$ of fixation point. On February 1 , 1949 after 6 injections vision was 0.6 in both eyes. On March 9, 1949, nasal and temporal fields had increased $3^{\circ}$ in both eyes. There was no improvement of the hemeralopia.

Case 12.-J.D.C., male, aged 36 years. Seen December 1, 1948. Typical retinis pigmentosa. Vision: R.E. 0.3 ; L.E. 0.5. Fields: R.E. constricted to within $5^{\circ}$ of fixation point, concentrically; L.E. the same, but extending to $9^{\circ}$ upon the temporal side of field only. After 18 injections vision was 0.6 in both eyes. By April, 1949, fields were of $10^{\circ}$ extending to $13^{\circ}$ on both nasal and temporal sides. Improvement in both hemeralopia and photophobia.

Case 13.-R.B.H., female, aged 45 years. Seen November, 1948. Typical retinitis pigmentosa. Vision: R.E. 0.25 ; L.E. 0.3 . Fields constricted in both eyes : R.E., nasal field reduced to $2^{\circ}$ and temporal to $5^{\circ}$ of fixation point; L.E., nasal field reduced to $2^{\circ}$ and temporal field to $4^{\circ}$. In January, 1949, after treatment, vision was $0.6^{\prime}$ in both eyes, and fields were both circular as follows: R.E. $5^{\circ}$ and L.E. $4^{\circ}$. Improvement was observed in both hemeralopia and photophobia.

Case 14.-A.V., male, aged 58 years. Seen October 4, 1948. Typical retinitis pigmentosa. Slight posterior opacities in both lenses. Hemeralopia. Photophobia. Vision: R.E. 0.5; L.E. 0.1; peripheral vision only, due to destructive lesion of the macula of the latter eye. Fields $10^{\circ}$ to $15^{\circ}$ from fixation point. After 15 injections vision in R.E. increased to 0.6; L.E. did not improve. After 40 injections vision unchanged. Hemeralopia no better. Photophobia decreased.

Case 15. - A.B., male. aged 47 years. Seen October 5, 1948. Retinitis pigmentosa. Vision: R.E. 0.4; L.E. fingers at $30 \mathrm{cms}$. Slight lenticular opacities. Field constricted almost to fixation point. Treatment was started with injections, and after stricted almost to fixation point. Treatment was started with injections, 0.7 and L.E. 0.04. Hemeralopia and photophobia 
distinctly improved. On November 5 an instillation was made and $30^{\prime}$ later vision was: R.E. $0 \cdot 9$ and L.E. $0 \cdot 1$. Treatment was continued with injections, and in March, 1949, improvement in vision persisted. Improvement of hemeralopia and photophobia, fields unchanged. Reading improved, so much so that patient who could previously only read a few paragraphs at a time, is now able to read a whole page of a newspaper.

Case 16.-L.B.F., female, aged 50 years. Seen September 21, 1948. Retinitis pigmentosa. Vision: 0.6 in both eyes. Hemeralopia and photophobia. Fields constricted to within $10^{\circ}$ of fixation point. Two injections were given per week, and after the fifth injection vision was 0.8 in both eyes. Hemeralopia and photophobia improved. Injections were continued and on November 8 vision was still 0.8 in both eyes. On this date an instillation was made and $30^{\prime}$ later vision reached unity in both eyes. Hemeralopia had decreased so considerably that patient was able to go out alone at night, which she had not been able to do for five years. A combined treatment was continued with, and on July 28, 1949, the improvement persisted without field changes.

Case 17.-A.P.Q., female, aged 44 years. Seen in October, 1948. Retinitis pigmentosa. Vision: R.E. 0.6; L.E. 0.02. Hemeralopia. Fields constricted to fixation point. Treated with injections from the first day. On November 5. 1948, vision was: R.E. 0.9 ; L.E. $0 \cdot 1$. Hemeralopia improved. Since then patient has not returned for observation.

Case 18.-T.S., male, aged 28 years. Seen February 24, 1949. Retinitis pigmentosa. Vision: 0.6 in both eyes. Fields constricted to within $5^{\circ}$ and $10^{\circ}$ of fixation point. Forty minutes after instillation vision increased to 0.9 in both eyes. On March 12, after having received two injections, these same values were found. After this, four more instillations were made, and on April 6 visual acuity reached unity in both eyes. Hemeralopia improved.

Case 19.-O.L., male, aged 42 years. Seen January 20, 1949. Retinitis pigmentosa. Vision: R.E. 0.04; L.E. 0.1. Fields constricted to within $2^{\circ}$ of fixation point. Combined treatment was given with both injections and instillations, without evident effects.

Case 20.-A.P., male, aged 25 years. Seen December 29, 1948. Retinitis pigmentosa. Vision: Finger movements at $30 \mathrm{cms}$. On March 4, 1949, after a combined treatment with subcutaneous injections and instillations, vision was: R.E. 0.04 ; L.E. counted fingers at one metre. On March 21 a retrobulbar injection of $0.5 \mathrm{ml}$. extract was made into the right eye. One hour later vision in that eye was 0.1 at a distance of 4 metres. From then until May 9 patient received two subcutaneous injections per week, and states that for the first time for a year he is able to go about the city unaccompanied, although with some difficulty. Excentric vision is now $0 \cdot 1$ in. R.E. and there have been no further changes in L.E.

Case 21.-M.P., male, aged 29 years. Seen March 29, 1949. Retinitis pigmentosa. Vision: R.E. 0.02; L.E. 0.04. Posterior lenticular opacities in both eyes. On April 28, 1949, after 8 instillations, there was no improvement.

Case 22.-P.V., male, aged 35 years. Seen April 11, 1949. Retinitis pigmentosa. Vision: R.E. unity; L.E. 0.6. Fields in the neighbourhood of $30^{\circ}$. On April 28, after two instillations, vision was unity in both eyes. Photophobia diminished. Before treatment was started, patient suffered from headache after reading or writing for two hours. This trouble has now disappeared.

\section{Results}

Out of a total of 22 patients treated, the results were favourable (as regards visual acuity) in sixteen (Cases $1,2,3,5,6,7,8,10$, $12,13,15,16,1 \%, 18,20,22)$, negative in two $(19$ and 21$)$, and doubtful in four $(4,9,11$, and 14).

Increase in vision has been as great as 0.8 (Case 1 ); it has been observed in patients with lenticular opacities of varying degree (Cases 1, 3, 6, 7, and 10), including two cases of simple glaucoma $(6$ and 10$)$. Hemeralopia improved in fourteen cases $(1,2,3,4,5$, 
$6,7,8,12,13,15,16,17$, and 18$)$; there was no improvement in seven, and of the remainder there are no data available. Out of thirteen patients with photophobia, ten improved.

The visual field was only studied in fourteen cases during treatment : in eight the field did not vary, while in six there were small increases of $2^{\circ}$ to $5^{\circ}$, in some cases concentrical and in others segmental. We believe that further observations will be necessary to decide upon the significance of these apparent increases in visual fields.

The increase in visual acuity was obtained in some cases with in jections (Cases 1, 2, 3, 5, 7, 12,13,14, 17, and 20), in others with instillations ( 8 and 22$)$, and in others again with a combined treatment $(6,10,15$, and 16$)$.

Of the three methods of administration of the extract (subcutaneous injection, instillation, and a combination of the two) we consider instillation to be the best. Thus, in two cases (15 and 16) after obtaining considerable improvement with a series of injections extending over several weeks, vision increased 0.2 in each case, $30^{\prime}$ after a single instillation. This efficacy combined with its simplicity makes instillation the ideal method.

As regards the duration of the improvement, our information is limited by the short time during which we have been using this medication. However, in our first patient treated (Case 3) the improvement has increased steadily for the last three years; the patient began with vision counting fingers, and now has vision 0.6 .

In those cases in which no result is obtained by our methods, it is suggested that a trial be made with subconjunctival and retrobulbar injections.

\section{Discussion}

In the first place we wish to point out that the success obtained in the treatment of retinitis pigmentosa with a pituitary extract in no way confirms the diencephalo-hypophyseal origin of this disease, inasmuch as this medication has been seen by us to give similar therapeutic results in the visual disorders of albinism and retinitis diabetica (Mussio-Fournier and others, 1949b, d, e), in high myopia (Conti and others, 1949), in hypertensive retinopathy, and in senile degeneration of the macula (Mussio-Fournier and others, $1949 \mathrm{c}$ )*.

As to the question of how the preparation employed reaches the retina, little can be said. However, since the application of

* Velter and others (1950) and Dollfus (1950) obtained favourable results in France with our pituitary extract, and similar results have been reported in Argentina by P. O. Cuzzani (1949) and B. Malamud (1949). 
the preparation to one eye favourably affected both, absorption and transportation by the blood would seem to be likely.

The third point to consider is the mechanism by which the substance acts. No doubt there is an action on the retina. The improvement of the hemeralopia, a disorder due to an alteration of the rods, indicates that the medication acts upon the latter. The increase in visual acuity observed is most likely due to an effect upon the cones*. Just as digitalis is beneficial in cardiac insufficiency, whatever the cause may be, so this extract increases the functional capacity of the retina in disorders of widely differing aetiology.

Throughout our researches we have borne in mind two hypotheses : first that the extract operates through a physiological action of the melanotropic hormone upon the vision; second that it acts through a non-hormonal pharmacological property.

The therapeutic success obtained by us latterly with instillations of an extract of muscle tissue in various disorders of the eye (retinitis pigmentosa, high myopia, diabetic retinopathy) seems to confirm the second hypothesis (Mussio-Fournier and others, 1949c).

Finally, it is to be remembered that Filatov, using implants and extracts of widely differing tissues, states he has obtained good results in various diseases of the eyes. We do not consider ourselves to be in a position to say, as yet, whether or not the active substance in our extract is the same as Filatov's " biogenic substances", but we wish to call attention to the simplicity of our instillation technique. As this treatment is not aetiologic but merely symptomatic, it would seem reasonable to suppose that the diseases of the eye thus treated will themselves continue their habitual chronic course. The exact percentage of improvement and average duration will only be obtained after further research.

\section{Summary}

Twenty-two cases of retinitis pigmentosa were treated with a pituitary extract, favourable results being obtained in sixteen. The mode of action of the extract is discussed, although it is not known what the active principle may be.

We are indebted to Laboratorios Senac, Montevideo, Uruguay, for their collaboration in preparing the extracts used in this research.

* The instillations of normal saline solution into the conjunctiva of several patients produced no effect, favourable results being obtained when pituitary extract was afterwards instilled, thus showing that this treatment does not act through psychotherapy. 


\section{REFERENCES}

BARDET, G. (1919-20). “ 'Sur un syndrome d'obésité congénitale avec polydactilie et rétinite pigmentaire"', Thesis, Paris.

BASILE, G. (1939). Ann. Ottalm., 67, 412.

BING, R. (1931). Norsk. Mag. Laegevidensk., 92, 956.

Conti, O., Mussio-Fournier, J. C., Carriguiry, P., and Gonzalez Vanrell, F. (1949). Dia méd. urug., 16, 311.

Cuzzani, T. O. (1949). Rev. Asoc. méd. arg., 63, 281.

Dollfus, M. A. (1950). Bull. Soc. Ophtal. France, p. 13.

Gonzalez VanRell, ;F., CarRiQuiry, P., and Conti, O. (1948). Dia. méd. urug., 15,3 . Paris, 65, 12 .

JoREs, A. (1933). Verh. dtsch. Ges. inn. Med., 45, 166.

Malamud, B. (1949). Sem. méd., B. Aires, 56, 1176.

Mussio-Fournier, J. C., Conti, O., Gonzalez Vanrell, F., and Carriguiry, P. (1949a). Bull. Acad. Méd. Paris, 113, 103.

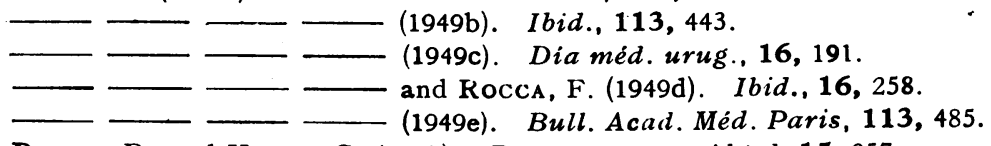

Pesme, P., and Hirtz, G. (1937). Rev. oto-neuro-ophtal.,15, 257.

Reilly, W. A., and Lisser, H. (1932). Endocrinology, 16, 337.

Sterling, W. (1930). Polsk. Gaz. Lek., 2, 889.

Velter, E., Desvignes, P., and Salmon (1950). Bull. Soc. Ophtal. France, , p. 9.

Vialléfont, H. (1936). Ann. Oculist., Paris, 173, 33.

ZoNDek, H., and Koenler, G. (1932). Dtsch. med. Wschr., 58, 2025. 